\title{
The Global Seamount Census
}

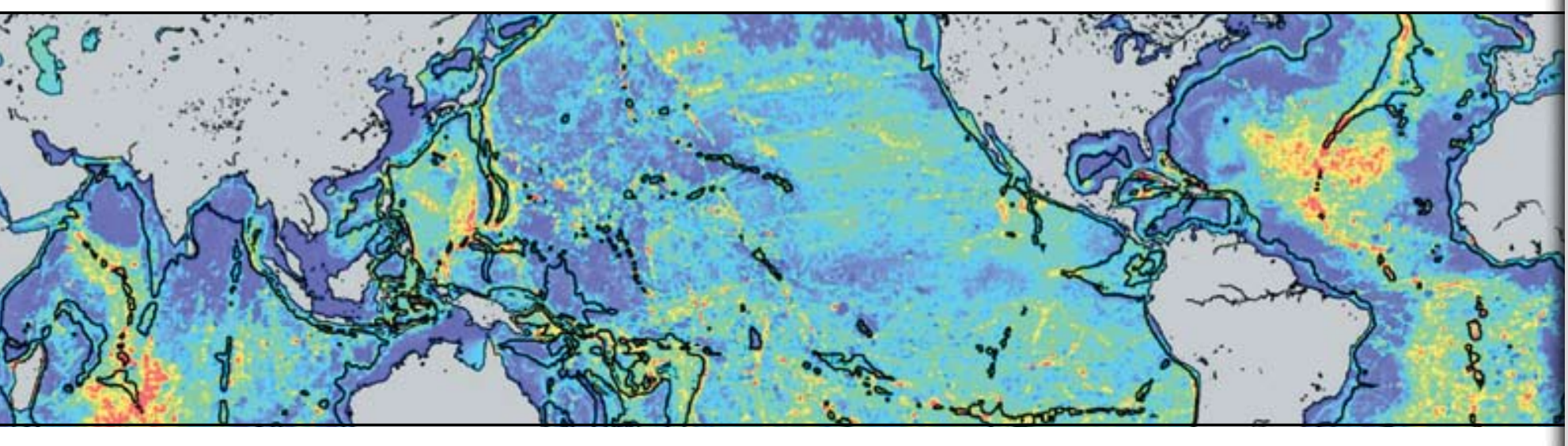

ABSTRACT. Seamounts are active or extinct undersea volcanoes with heights exceeding $\sim 100 \mathrm{~m}$. They represent a small but significant fraction of the volcanic extrusive budget for oceanic seafloor and their distribution gives information about spatial and temporal variations in intraplate volcanic activity. In addition, they sustain important ecological communities, determine habitats for fish, and act as obstacles to currents, thus enhancing tidal energy dissipation and ocean mixing. Mapping the complete global distribution will help constrain models of seamount formation as well as aid in understanding marine habitats and deep ocean circulation. Two approaches have been used to map the global seamount distribution. Depth soundings from single- and multibeam echosounders can provide the most detailed maps with up to 200 -m horizontal resolution. However, soundings from the $>5000$ publicly available cruises sample only a small fraction of the ocean floor. Satellite altimetry can detect seamounts taller than $\sim 1.5 \mathrm{~km}$, and studies using altimetry have produced seamount catalogues holding almost 13,000 seamounts. Based on the size-frequency relationship for larger seamounts, we predict over 100,000 seamounts $>1 \mathrm{~km}$ in height remain uncharted, and speculatively 25 million $>100 \mathrm{~m}$ in height. Future altimetry missions could improve on resolution and significantly decrease noise levels, allowing for an even larger number of intermediate (1-1.5-km height) seamounts to be detected. Recent retracking of the radar altimeter waveforms to improve the accuracy of the gravity field has resulted in a twofold increase in resolution. Thus, improved analyses of existing altimetry with better calibration from multibeam bathymetry could also increase census estimates. 


\section{INTRODUCTION}

Seamounts are among the most ubiquitous landforms on Earth but are unevenly distributed among the ocean basins. Traditionally, seamounts are defined as isolated underwater volcanic constructs that reach at least $1,000 \mathrm{~m}$ in height from base to summit (Menard, 1964; International Hydrographic Organization, 2008), but modern research recognizes seamounts as small as $50-100 \mathrm{~m}$ in height (e.g., D. Smith and Cann, 1990). Seamounts are generally found on oceanic crust and less frequently on extended continental crust. They are produced near mid-ocean spreading ridges, in plate interiors over upwelling mantle plumes (hotspots), and in island-arc convergent settings (Staudigel and Clague, 2010). Seamounts are important for many disciplines such as geology, oceanography, biology, ecology, and possibly the economy (considering future harvesting of mineral resources). Because the ocean is vast, research vessels have visited only a few thousand of them, arguably identifying seamounts as the last major frontier in geographic, geological, and ecological exploration on planet Earth.

The most direct way of detecting and characterizing seamounts is bathymetric mapping (Figure 1a). However, the ocean remains far from adequately mapped (only $10 \%$ at 1 -minute resolution [Becker et al., 2009]), with large gaps between ship tracks, especially in the southern oceans. Seamounts are relatively small features compared to the scale of ocean basins, and most seamounts have yet to be surveyed by echosounders. Satellite altimetry presents an alternative approach to detect seamounts (Figure 1b). The density contrast between seamounts and water gives rise to gravity anomalies that perturb the geoid, an equipotential surface approximated by the sea surface. Altimeters can measure these perturbations, and processing can isolate their causes (i.e., seamounts). However, there are assumptions and uncertainties in this approach that need to be considered.

Here, we briefly review results from both direct bathymetric and indirect altimetric mapping of seamounts, what the uncertainties are, and why smaller seamounts may be under-represented. For clarity, we follow Pitcher et al. (2007) and separate small from large seamounts at the height limit of $1500 \mathrm{~m}$, which is the current threshold for characterizing seamounts with satellite altimetry. We then discuss why global estimates of seamount counts can vary considerably, depending on the methodology employed and the definition of a seamount. Finally, we discuss uncertainties in these estimates and arrive at our best estimates for the global census of seamounts.

\section{BATHYMETRIC SEAMOUNT STUDIES}

Bill Menard began the modern era of seamount statistics studies, defining a seamount as "an isolated elevation from the seafloor with a circular or elliptical plan, at least $1 \mathrm{~km}$ of relief, comparatively steep slopes and a relatively small summit area" (Menard, 1964). Examining $\sim 5 \times 10^{5} \mathrm{~km}$ of narrow single-beam bathymetric profiles from the Pacific, he found $\sim 1000$ seamounts that fit his definition. Extrapolating to the entire Pacific, he predicted $\sim 10,000$ seamounts $>1 \mathrm{~km}$ in elevation. Later studies have relaxed the 1-km limit and routinely study seamounts as small as $\sim 100 \mathrm{~m}$.

A particular difficulty with singlebeam profiles is not knowing what part of the seamount was transected; thus, the apparent height may at times be underestimated. Jordan et al. (1983) derived expressions to account for apparent height bias and applied them to $44,000 \mathrm{~km}$ of wide-beam profiles in the Pacific. They argued that the inferred seamount size distribution had an exponential falloff with increasing size; extrapolation of their results from seamounts with heights of 300-1500 m predicts 30,000-50,000 large Pacific seamounts. Seamount populations were found to differ significantly in different parts of the Pacific, making extrapolations from a small, well-surveyed area to a global estimate problematic. Typically, smaller seamounts form near mid-ocean ridges with off-axis production, and larger ones result from intraplate volcanism (Batiza, 1982; D. Smith and Jordan, 1988). Following the advent of multibeam profiling in the early 1980s, several researchers began to reexamine the topic of seamount abundance using swath bathymetry, concluding that seamount abundances could be well described by either exponential or power-law relationships (Abers et al., 1988). Because most multibeam coverage coincides with young seafloor, most studies have examined the distribution of small seamounts near mid-ocean ridges, using closed-contour analysis to identify and characterize seamounts as small as $50 \mathrm{~m}$ in height (Cochran, 2008; Jaroslow et al., 2000; D. Smith and Cann, 1992). Because of the small area examined, extrapolations to global populations are subject to large uncertainties.

Relying on a new technique called 

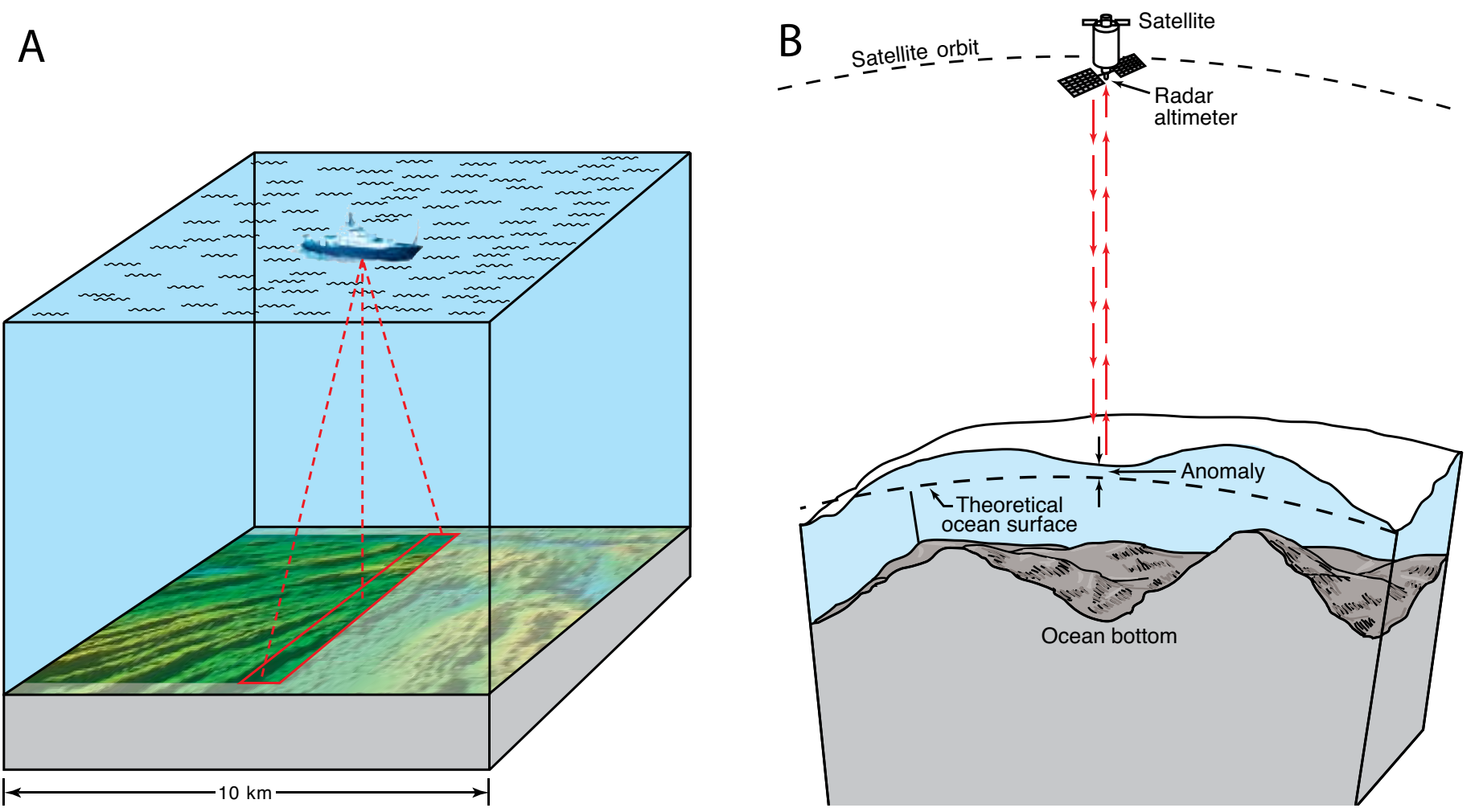

Figure 1. Modern tools for mapping the deep ocean floor. (a) Shipboard multibeam echosounders use sound waves to map 10-20-km wide swaths at 200-m horizontal resolution. (b) An Earth-orbiting radar cannot see the ocean bottom, but it can measure ocean surface height variations induced by ocean floor topography. Although the resolution of the echosounder technique is far superior to the ultimate resolution of the satellite altimeter technique ( $8 \mathrm{~km})$, complete mapping of the deep ocean using ships would take 200 ship-years at a cost of billions of dollars (Carron et al., 2001). Indeed, the shipboard and altimeter methods are highly complementary. The current distribution of ship soundings provides long-wavelength (> $160 \mathrm{~km}$ ) information that cannot be obtained from gravity because of spatial variations in isostasy. Satellite altimeters provide global uniform coverage in the 16-160-km wavelength band. When interesting features are discovered in satellite gravity, they can be surveyed in fine detail by ships. Modified from Sandwell et al. (2006)

MiMIC (Micro Macro Interpretation Construct; Hillier and Watts, 2004) to isolate seamount-like features from single-beam bathymetric profiles, Hillier and Watts (2007) examined the global track-line database and found over 200,000 seamounts exceeding $100 \mathrm{~m}$ in height in the world ocean between $60^{\circ} \mathrm{S}$ and $60^{\circ} \mathrm{N}$ latitude. Given the lack of complete global track-line coverage, this estimate is likely on the low side. Many of the smaller features are likely to be nonvolcanic seamounts (e.g., abyssal hills). Nevertheless, this estimate is, at present, the most complete global seamount census derived entirely from shipboard bathymetric profiles.

\section{ALTIMETRIC}

\section{SEAMOUNT STUDIES}

Although the smallest seamounts can only be imaged by high-resolution multibeam echosounders, larger seamounts may be observed indirectly via perturbations of Earth's gravity field (Figure 1b). Craig and Sandwell (1988) performed the first global analysis of Seasat altimetry profiles and identified 8556 seamounts. Despite this success, many seamounts were missed or were incompletely described as a consequence of the large spacing $(\sim 100 \mathrm{~km})$ between satellite ground tracks. More recent global estimates of seamount abundances were based on improved satellite altimetry, specifically the
Geosat/ERS-1 gridded products (for details, see Sandwell and Smith, 1997, 2009; W. Smith and Sandwell, 1997). For instance, Wessel and Lyons (1997)

Paul Wessel (pwessel@hawaii.edu) is Professor, Department of Geology and Geophysics, School of Ocean and Earth Science and Technology, University of Hawai 'i, Honolulu, HI, USA. David T. Sandwell is Professor, Scripps Institution of Oceanography, University of California at San Diego, La Jolla, CA, USA. Seung-Sep Kim is PhD Candidate, Department of Geology and Geophysics, School of Ocean and Earth Science and Technology, University of Hawai ${ }^{i}$, Honolulu, HI, USA. 
developed a procedure for detecting and characterizing large seamounts in the Pacific, and Wessel (2001) extended this analysis to the global ocean, subject to the $\pm 72^{\circ}$ limit on latitude. These studies identified almost 15,000 seamounts globally (now revised to $\sim 12,000$, as accidental duplications of seamounts from plates with low counts inflated the original estimates). By design, neither of these two studies included island arc seamounts.

Over the ocean, the main causes of free-air gravity anomalies are lateral density variations related to undulations of the seafloor. Because basalt is much denser than seawater, the gravity field over a seamount is locally enhanced. However, large seamounts deform the seafloor, and this deformation also gives rise to gravity anomalies, but of opposite sign. Conveniently, these anomalies tend to be of longer wavelengths than those due to the seamount itself, making it possible to study the relationship between seafloor topography and observed gravity in a limited band of wavelengths. W. Smith and Sandwell (1997) used this technique to make predictions of the relative seafloor relief, given the observed gravity anomalies, and then added in regional depths based on available ship-track bathymetry measurements. The resulting gridded bathymetry product is the best global solution available for bathymetry as it uses actual bathymetry measurements to calibrate the bathymetric predictions. Kitchingman and Lai (2004) used the predicted bathymetry incorporated into the ETOPO2 grid (National Geophysical Data Center, 2006) to determine seamounts. Using standard GIS algorithms, they identified isolated highs in the bathymetry grid. Depending on the exact technique used and a lateral size threshold, as many as 142,000 seamounts taller than $100 \mathrm{~m}$ were identified (Kitchingman et al., 2007).

\section{ALTIMETRY UNCERTAINTIES, ERRORS, AND OMISSIONS}

There are five key issues that affect the ability of satellite altimetry to detect and characterize seamounts: upward continuation, characteristic wavelengths, altimetry noise level, seafloor roughness, and sediment coverage. These effects combine to place limits on how small seamounts may be detected and interpreted.

\section{Upward Continuation}

Upward continuation is a fundamental law of physics that causes the gravitational signal originating at the water/ rock interface to attenuate exponentially with distance away from the seafloor. Short wavelengths $(\lambda)$ are attenuated more than long wavelengths - the decay follows $\exp (-k z)$, where $k=2 \pi / \lambda$ is the wave number and $z$ the water depth. As a general rule, features narrower than about the mean ocean depth cannot be mapped, so seamounts with basal diameters less than $4 \mathrm{~km}(\sim 1-\mathrm{km}$ tall $)$ cannot be detected by satellite altimetry unless they occur on the shallow continental margins (Figure 2).

\section{Characteristic Wavelengths}

The attenuated gravitational signal over a seamount has a range of wavelengths. However, the shortest wavelengths are not recovered by existing pulse-limited satellite measurements. Currently available data have typical track spacing at

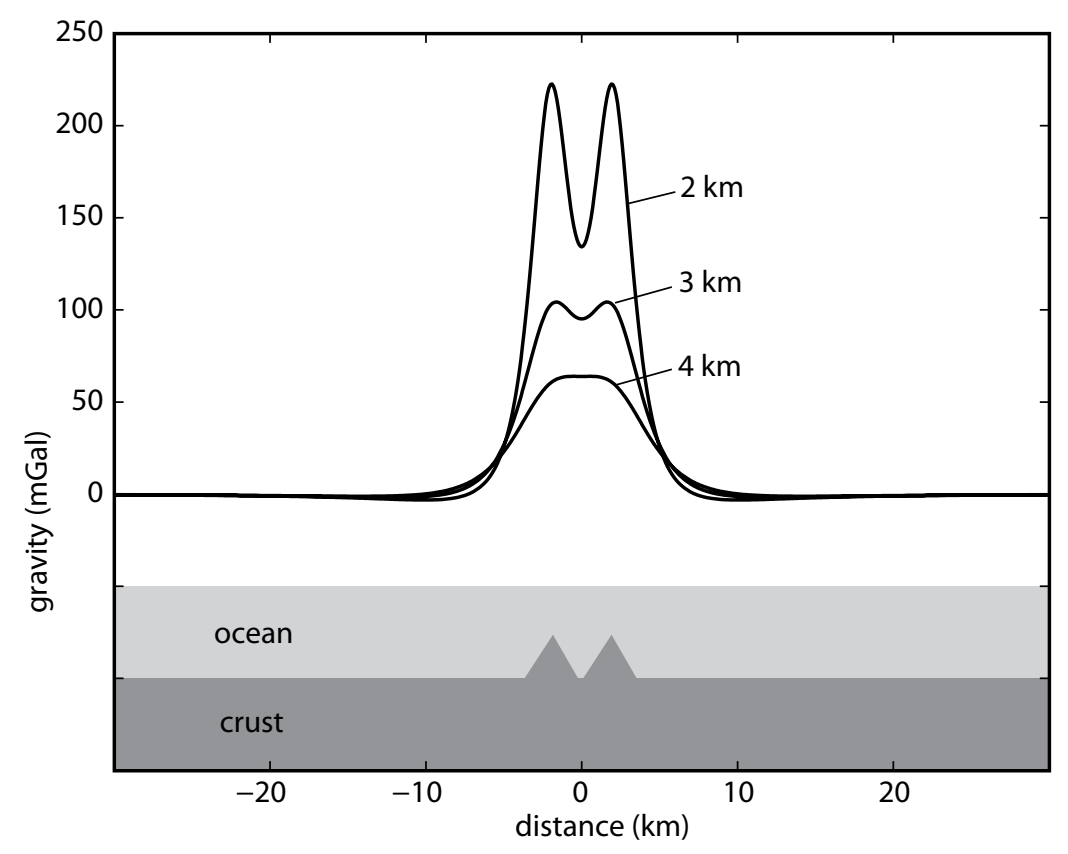

Figure 2. Fundamental limitations of topographic recovery from gravity anomaly measurements over seamounts. Gravity signatures of the closely spaced seamounts ( $4 \mathrm{~km}$ apart and $1 \mathrm{~km}$ tall) are strong and distinct when the average ocean depth is $2 \mathrm{~km}$ or less, but their signatures combine and become weak when the ocean depth is $4 \mathrm{~km}$. This is the upward continuation effect. Modified from W. Smith and Sandwell (2004) 
the equator of $4 \mathrm{~km}$, and the radar footprint size is typically $4 \mathrm{~km}$, so detecting features narrower than about $8 \mathrm{~km}$ requires a new altimeter mission. To match the range of wavelengths in both predicted and observed gravity data, some researchers band-pass filtered the observed, while others low-pass filtered the predicted, before comparing them (e.g., Wessel and Lyons, 1997). In either case, filtering further reduces amplitudes and makes it harder to identify small seamounts. Furthermore, for seamount modeling, prediction of heights and basal radii can be biased due to incomplete matches between the predicted and observed wavelengths.
Altimetry Noise Level

The ability to detect and map seamounts also depends on the noise in the gravity field. The major altimeter noise source is caused by ocean surface roughness due to ocean waves (Figure 3 ). This noise can be reduced somewhat by improved altimeter technology and repeated measurements. To date, eight radar altimeter missions have logged 63 years of sea surface height measurements. However, only a small fraction (2.4 years or $4 \%$ ) of these data have spatially dense ground tracks that are suitable for gravity field recovery and seamount searches. Most of the 63 years of altimeter data were collected from the repeat orbit configuration that is optimal for recovering changes in ocean surface height associated with currents and tides. The only sources of nonrepeat altimeter data are the geodetic phases of Geosat (18 months) and ERS-1 (11 months) (Sandwell and Smith, 2009).

\section{Seafloor Roughness}

One difficulty with counting the number of seamounts globally is that small seamounts can be confused with the abyssal hill fabric (Figure 3). Abyssal hills are generated at mid-ocean ridges by a combination of volcanism and normal faulting (e.g., Lonsdale, 1977; Macdonald et al., 1996; Macdonald and Luyendyk,

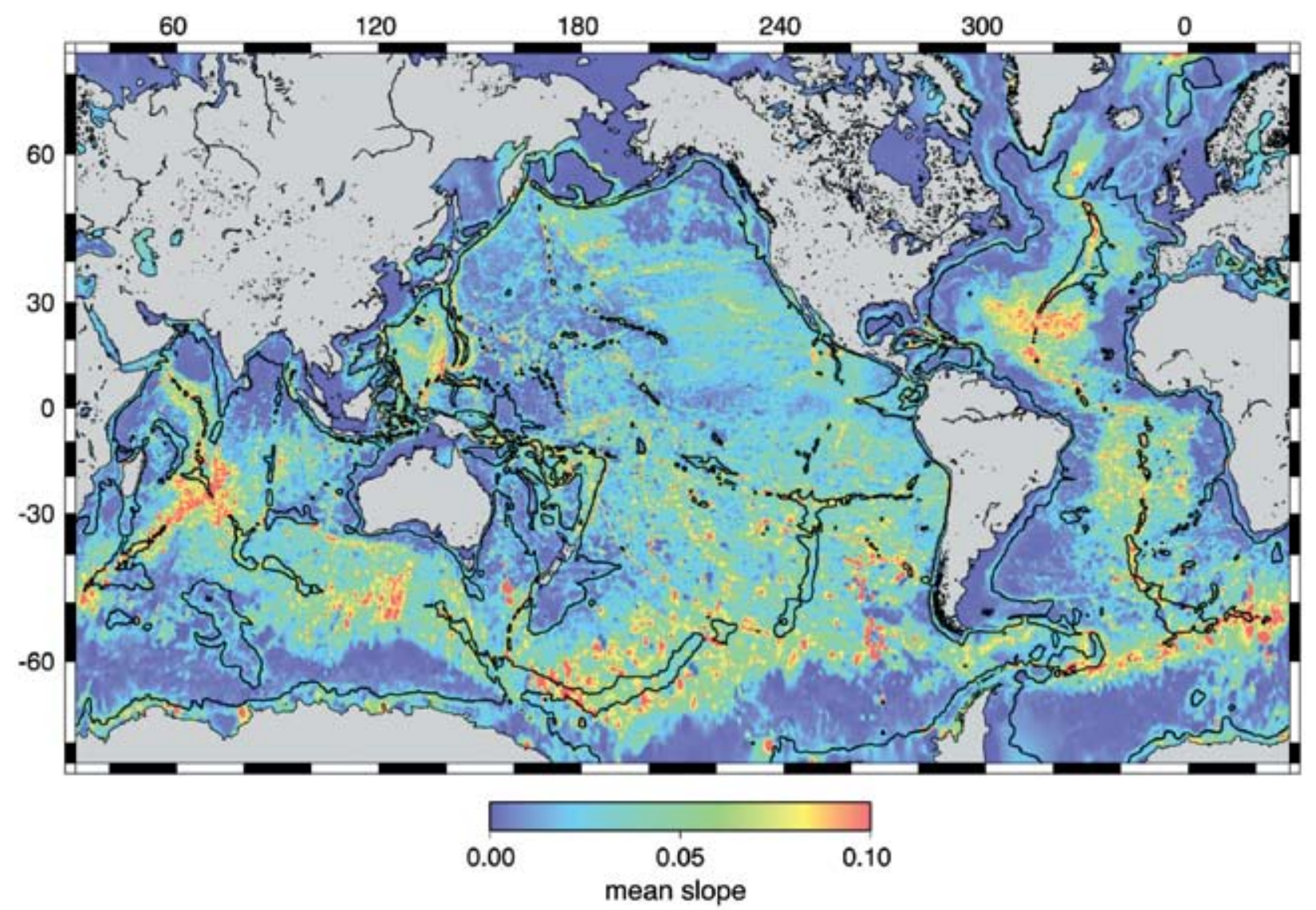

Figure 3. Mean slope of the seafloor from ship soundings, including contributions from abyssal hills, fracture zones, and seamounts. The 3000-m-depth contour line highlights the deep ocean basins. Mean slope commonly exceeds 0.05 on the flanks of the seafloor spreading ridges, especially the ridges spreading at a rate of $<70 \mathrm{~mm} \mathrm{yr}^{-1}$ (Becker and Sandwell, 2008). 
1985). The amplitude and wavelength of abyssal hills depend strongly on the rate of seafloor spreading (Goff, 1991; Goff et al., 2004; Malinverno and Cowie, 1993; W. Smith, 1998). Abyssal hills and fracture zones on the flanks of slow spreading ridges commonly have topographic amplitude greater than $1 \mathrm{~km}$, so distinguishing seamounts from abyssal hills is often problematic.

\section{Sediment Cover}

On older seafloor, sediment thickness can exceed $1 \mathrm{~km}$, which will bury the more numerous small seamounts. As Figure 4 shows, sediments commonly exceed 500-m thickness on older seafloor, especially adjacent to continental margins and along equatorial regions. Sediment thickness exceeds $2 \mathrm{~km}$ on oceanic crust offshore of major river deltas and ice streams such as the Bay of Bengal, Gulf of Mexico, offshore Antarctica, and offshore Greenland. An interesting aspect of sedimentation is that while the topographic expression of the seamount has disappeared, a portion of its gravity signature will remain because the sediment density is generally less than the basement density. Such buried seamounts are still relevant as part of a global geochemical or geological record (e.g., Staudigel and Clague, 2010), and they are likely to play a role in the hydrothermal circulation of the oceanic crust (Fisher and Wheat, 2010). Hydrothermal circulation can have an important effect on seafloor biology, so identifying the locations of buried seamounts could be important.

\section{THE THRESHOLD OF DETECTION FROM SATELLITE ALTIMETRY}

Overall, the five factors described above-upward continuation, characteristic wavelengths, altimetry noise level, seafloor roughness, and sediment cover-will confuse the census of smaller seamounts. An improved altimeter mission with lower noise may reveal the

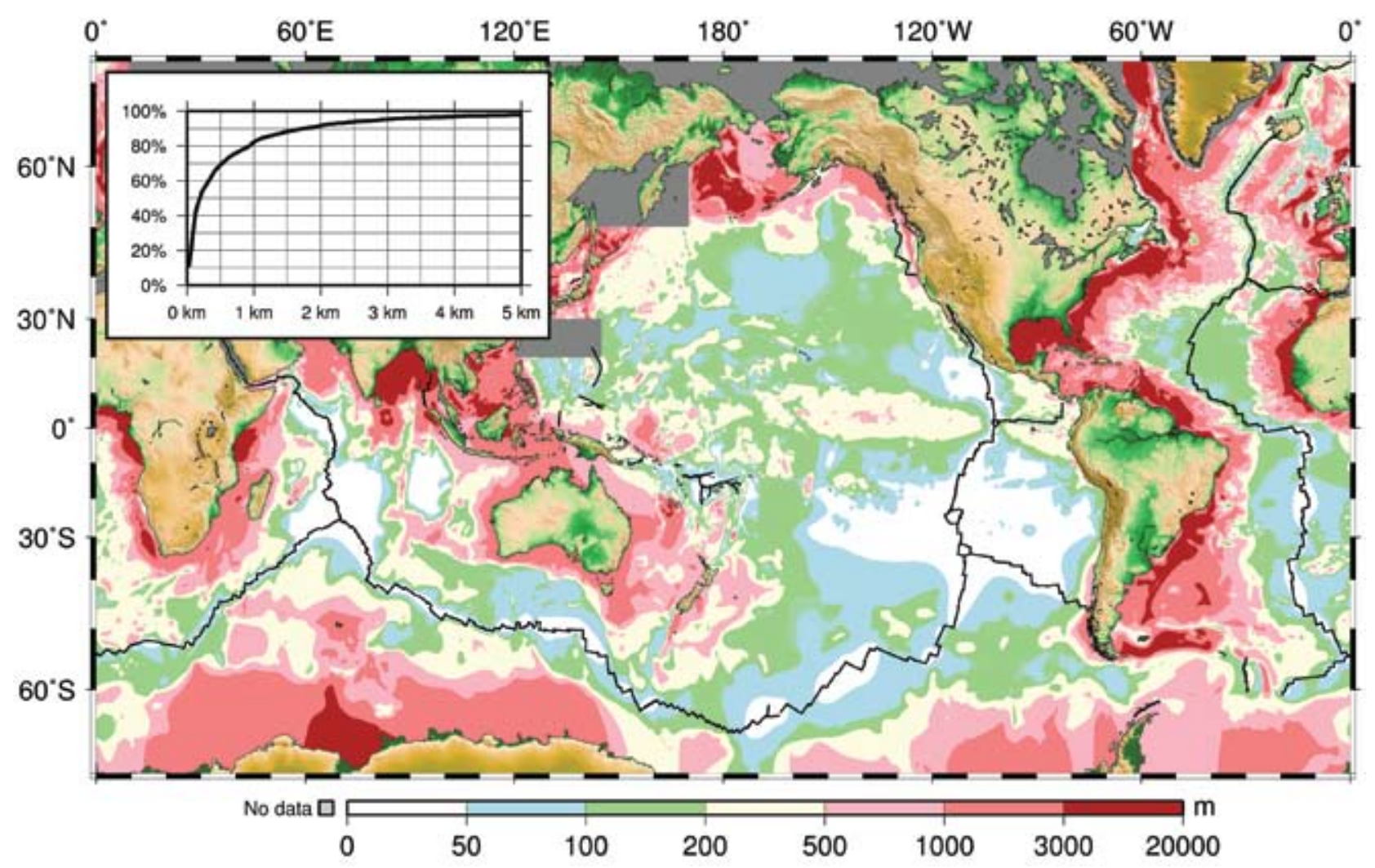

Figure 4. Observed sediment cover in the ocean. Over $60 \%$ of the seafloor has less than $200 \mathrm{~m}$ of sediment cover, making the detection of smaller seamounts possible. Inset: Cumulative areal distribution of sediment thickness. 
gravity expressions of all topographic features taller than $1 \mathrm{~km}$, although upward continuation will remain a fact of nature, preventing global mapping of most smaller seamounts $(<1 \mathrm{~km})$ in deeper water from space. However, it is likely that tens of thousands of small seamounts in the $1-1.5-\mathrm{km}$ height range could be reliably detected if improved satellite altimetry were to become available in the future (Sandwell et al., 2002). Even with complete mapping of seamount-like gravity expressions, distinguishing between abyssal hills and seamounts will be problematic on the flanks of the slower spreading ridges. In addition, sediment burial will reduce or mask the topographic expressions of smaller seamounts.

To explore the limits on detection (Figure 5), we used a truncated cone model adapted to approximate the typical shape of seamounts, with basal radius of 4.5 times the height (Wessel, 2001). Apart from seamount height and water depth, other parameters that affect the vertical gravity gradient (VGG) amplitudes are seamount and sediment

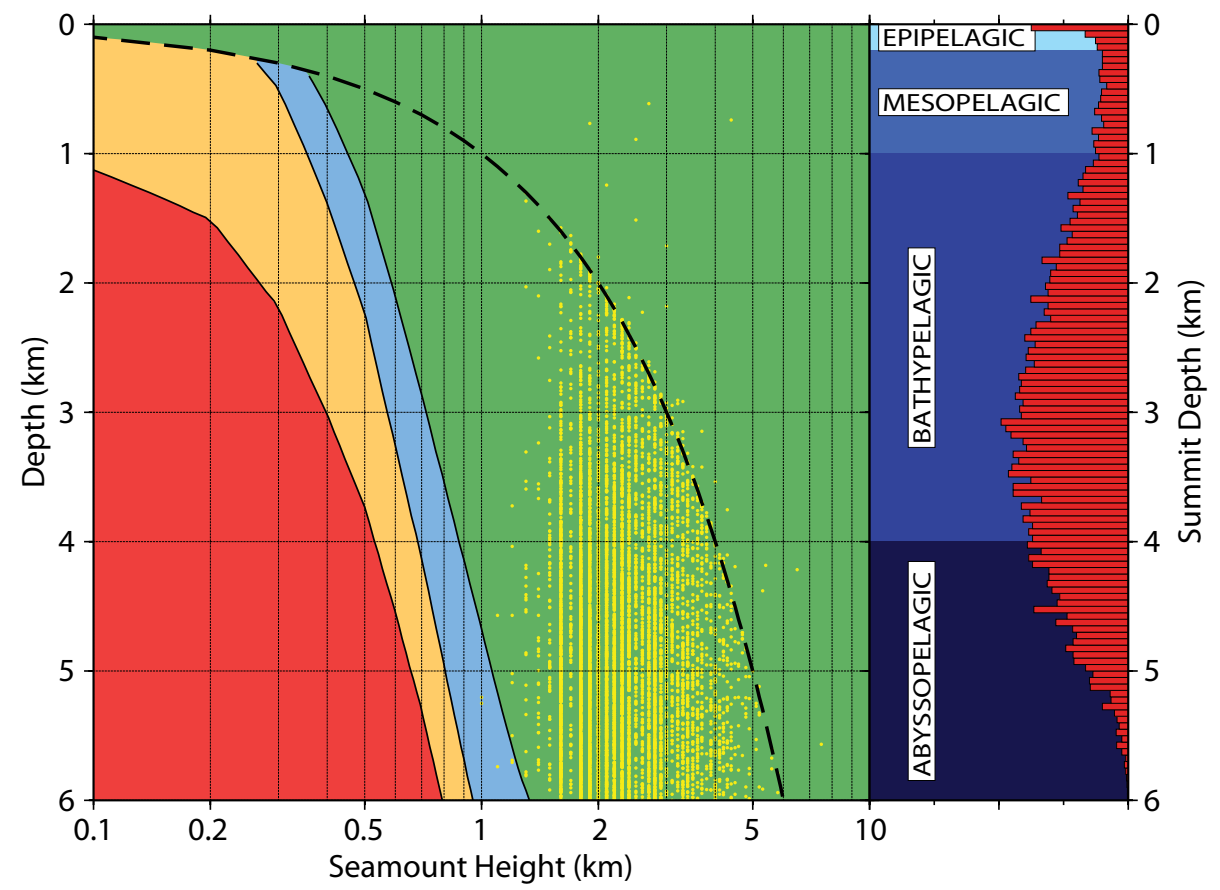

Figure 5. Prediction of seamount sizes detectable from satellite-derived vertical gravity gradients. The figure is based on modeling the maximum vertical gravity gradient amplitude over truncated cones of various sizes and densities, with or without sediment cover, for a range of water depths, and with different noise levels (see text for details). Seamounts are classified by size as a function of water depth into various degrees of "detectability" (red to green colors). Seamounts in the green zone should be easily detected, whereas those in the red zone are too small and too deep to give a signal exceeding the background noise level. It may be possible to detect seamounts in intermediate domains (blue, orange) using a robust methodology or better data (see text for details). Yellow dots are height estimates (Wessel, 2001) based on older data; note that some islands were included (exceeding the dashed line where height = depth), but this is partly due to errors in estimating regional depths from bathymetry grids. Interestingly, the histogram of summit depths follows a normal distribution centered on a 3-km depth, with large and shallow seamounts appearing as outliers, possibly due to coral growth. densities, sediment thickness, noise level of the observed data (or background "noise" represented by abyssal hills), and characteristic wavelengths of the VGG anomaly. We considered various models by changing these parameters and determined "detectability," defined as seamounts with VGG amplitudes higher than the noise threshold; this threshold was set to three times the standard deviation of VGG anomalies observed in an area of the Pacific devoid of seamounts. Given the sediment coverage (Figure 4), we estimated the typical range of sediment thicknesses for a given water depth (a proxy for seafloor age). In addition, we applied a second-order, low-pass Butterworth filter with a cutoff wavelength of $18 \mathrm{~km}$ to the predicted signals in order to simulate a typical observed VGG spectrum (e.g., Marks, 1996). Seamounts most likely to be detected (green domain) all have VGG amplitudes above our higher noise level (15 Eötvös; 1 Eötvös $=0.1 \mathrm{mGal} \mathrm{km}^{-1}$ ), even when a maximum sediment thickness and the smallest density contrast between seamount $\left(2500 \mathrm{~kg} \mathrm{~m}^{-3}\right)$ and sediment $\left(2300 \mathrm{~kg} \mathrm{~m}^{-3}\right)$ were considered. Lesslikely-to-be-detected seamounts (blue domain) have VGG amplitudes barely above a lower noise level (10 Eötvös) despite a minimum sediment thickness and the largest density contrast between seamount $\left(2800 \mathrm{~kg} \mathrm{~m}^{-3}\right)$ and sediment $\left(2000 \mathrm{~kg} \mathrm{~m}^{-3}\right)$. Hard-to-detect seamounts (orange domain) have VGG amplitudes barely above the lower noise level when the less-dense seamount $\left(2500 \mathrm{~kg} \mathrm{~m}^{-3}\right)$ and no sediment coverage were considered. Finally, red zone seamounts have gravity signals that are attenuated below the lower noise level due to upward continuation; thus, their VGG 
amplitudes are not likely to be detected in the present satellite-derived data. We omitted the low-pass filter for the boundary between the orange and red domains. Red zone seamounts, therefore, are mainly constrained by upward continuation. Yellow circles indicate the global population found by Wessel (2001). These estimates were based on a 1996 version (v. 7.2) of the VGG data; the latest data processing has improved the signal-to-noise ratio more than twofold (Sandwell and Smith, 2009). Furthermore, the Wessel (2001) method used to characterize the seamounts employed a 30 Eötvös noise limit and imposed a circular symmetry that clearly is not optimal for detecting the more elliptical seamounts. These shortcomings in methodology and the recent improvement in data processing, combined with the analysis presented in Figure 5, suggest many more seamounts could be detected with a revised analysis of the existing altimetry data, should new data become available in the future.

\section{THE GLOBAL}

\section{SEAMOUNT CENSUS}

As mentioned, the ambiguity of the source of the gravity signals means the census of smaller seamounts will depend somewhat on the applicationgeology, biology, or ocean mixing. For instance, whereas Wessel (2001) reported nearly 12,000 seamounts, Kitchingman and Lai (2004) reported 8,500-142,000 seamounts (depending on parameter settings) by using the ETOPO2 grid. These differences are partly found in methodology, but they are also related to the definition of a seamount. While Wessel (2001) was attempting to identify intraplate

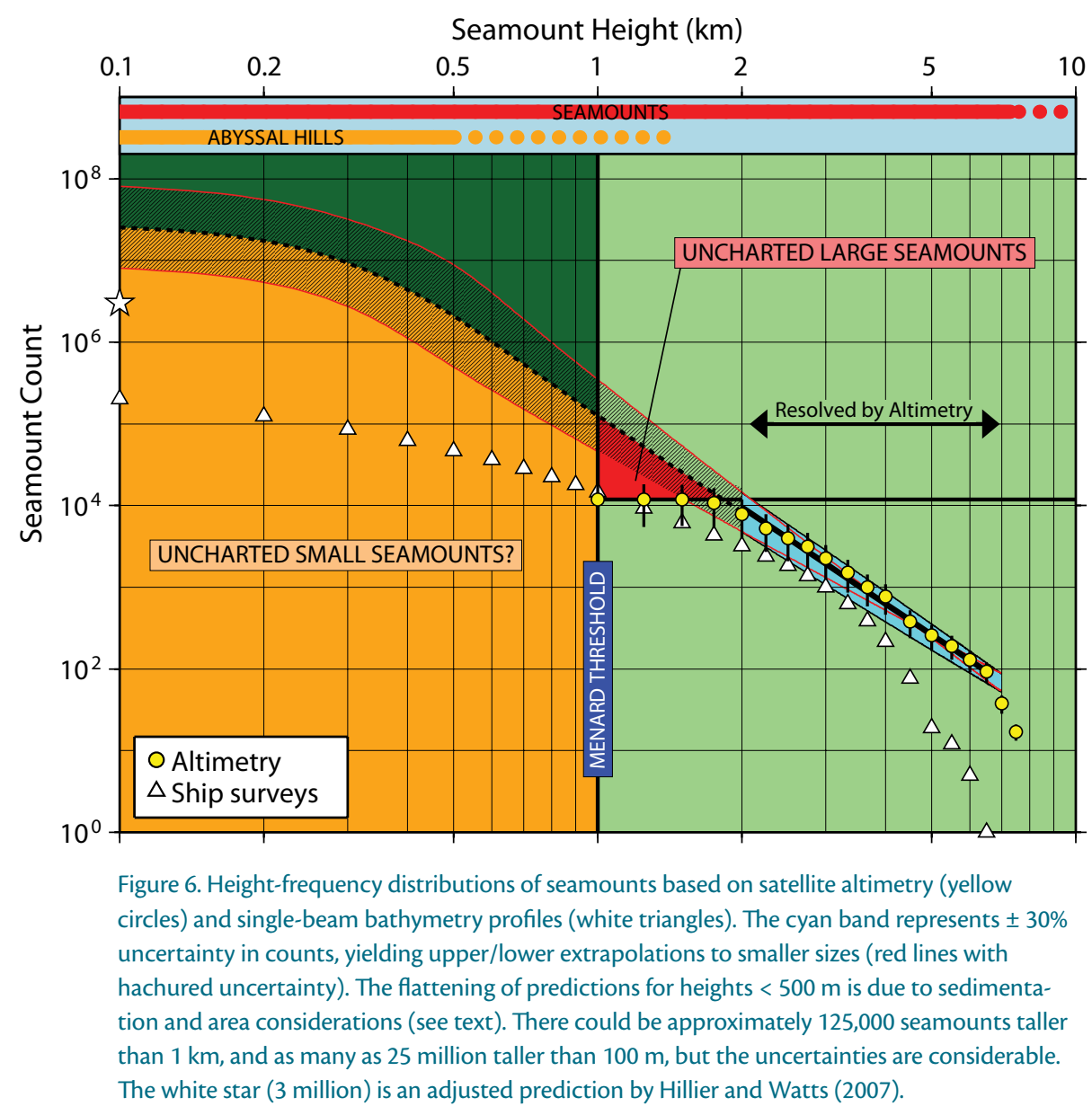

volcanoes (which excludes island arcs and abyssal hills), Kitchingman and Lai (2004) were including any local isolated peak, such as uplifted blocks and abyssal hills, especially near midocean ridges. However, it should be noted that ETOPO2, which in the ocean derives mostly from the predicted bathymetry of W. Smith and Sandwell (1997), degraded the original signal by resampling the data (Marks and Smith, 2006). Furthermore, the high end of the ETOPO2 seamount census used a size threshold much smaller than the resolution of the predicted data.

Figure 6 summarizes our present knowledge of the global seamount size-frequency distribution. The most complete coverage of large seamounts comes from altimetry, whose cumulative distribution shows a clear power-law relationship (yellow circles). However, because of the limitations discussed earlier, smaller seamounts are underrepresented. In contrast, bathymetric studies (Hillier and Watts, 2007) do not suffer the same degradation in resolution with size and can thus detect smaller (> $100 \mathrm{~m}$ ) seamounts (white triangles), but they completely miss all seamounts lying between the sparse ship tracks. To complicate matters, populations of volcanic seamounts and abyssal hills increasingly overlap for smaller sizes. Nevertheless, bathymetry and altimetry agree on a power-law relationship where their distributions overlap (2-5 km). Hillier and Watts (2007) used this 
correlation and offset to adjust their counts, resulting in a revised prediction of 3 million seamounts larger than $100 \mathrm{~m}$ (white star).

We extrapolated the trends from altimetry down to $100 \mathrm{~m}$, using a $30 \%$ uncertainty on the altimetrydetermined heights (Wessel and Lyons, 1997). However, at smaller sizes, these predictions must be eclipsed by considerations of sedimentation and available space. Thus, we evaluated the seafloor area deeper than mid-ocean ridge depths $(\sim 2500 \mathrm{~m})$ and, for a given seamount size, subtracted the area with a sediment thickness exceeding the seamount height. The remaining area was divided by the seamount's footprint, yielding an upper limit on the number of seamounts that would fit (upper red line). Our lower limit was defined as one order of magnitude lower, with uncertainties represented by the hachured area. Given population of 25 million, but it could range from 8-80 million. Clearly, extrapolating our model this far makes for speculative estimates.

Note that while our predictions are based on seamount statistics that excluded island arcs, the small area of island arcs relative to the large ocean basins suggests this omission is relatively small and well within the large error estimates in Figure 6. Nevertheless, future global altimetric studies will hopefully include this class of seamounts as well.

\section{CONCLUSIONS}

Seamounts range in height from 50-100 $\mathrm{m}$ to over $8 \mathrm{~km}$, breaching the sea surface and becoming islands at the higher elevations. Many of the larger seamounts are found in linear seamount chains and were formed by mantle plumes; in contrast, smaller seamounts are formed on young lithosphere near a

...IMPROVED ANALYSIS OF CURRENT ALTIMETRY DATA AND BETTER CORRELATION AND VALIDATION WITH MULTIBEAM BATHYMETRY COULD REDUCE THE UNCERTAINTIES

\section{ASSOCIATED WITH OUR CURRENT ESTIMATES}

\section{OF SEAMOUNT ABUNDANCES.}

these calculations and assumptions, we estimate the population of seamounts $>1 \mathrm{~km}$ in height to be $\sim 125,000$, but it could range from 45,000-350,000. For heights $>100 \mathrm{~m}$, the uncertainties are much larger; our model predicts a mid-ocean ridge. Most small seamounts $(<1 \mathrm{~km})$ can only be adequately studied using ship bathymetry, whereas larger seamounts can be identified on a global scale using altimetry. It is difficult to reconcile the size-frequency statistics derived from the two approaches because multibeam surveys only cover a fraction of the ocean floor, whereas altimetry coverage is almost complete. Global, single-beam analysis suggests, however, that the results may be complementary. The biggest improvement in such studies would come from new and higher-quality altimetry data. In the meantime, improved analysis of current altimetry data and better correlation and validation with multibeam bathymetry could reduce the uncertainties associated with our current estimates of seamount abundances. Finally, we hope the availability of the seamount search tool (see Box 3 on page 34 of this issue [Sandwell and Wessel, 2010]) will lead to better use of available ship time, especially during transit legs, to target uncharted seamounts. 迎

\section{REFERENCES}

Abers, G.A., B. Parsons, and J.K. Weissel. 1988. Seamount abundances and distributions in the southeast Pacific. Earth and Planetary Science Letters 87:137-151.

Batiza, R. 1982. Abundances, distribution, and sizes of volcanoes in the Pacific Ocean and implications for the origin of non-hotspot volcanoes. Earth and Planetary Science Letters 60:195-206.

Becker, J.J., and D.T. Sandwell. 2008. Global estimates of seafloor slope from single-beam ship soundings. Journal of Geophysical Research 113, C05028, doi:10.1029/2006JC003879.

Becker, J.J., D.T. Sandwell, W.H.F. Smith, J. Braud, B. Binder, J. Depner, D. Fabre, J. Factor, S. Ingalls, S.-H. Kim, and others. 2009. Global bathymetry and elevation data at 30 arc seconds resolution: SRTM30_PLUS. Marine Geodesy 32(4):355-371.

Carron, M.J., P.R. Vogt, and W.-Y. Jung. 2001. A proposed international long-term project to systematically map the world's ocean floors from beach to trench: GOMAP (Global Ocean Mapping Program). International Hydrographic Review 2(3):49-50.

Cochran, J.R. 2008. Seamount volcanism along the Gakkel Ridge, Arctic Ocean. Geophysical Journal International 174:1,153-1,173. 
Craig, C.H., and D.T. Sandwell. 1988. Global distribution of seamounts from Seasat profiles. Journal of Geophysical Research 93(B9):10,408-10,420.

Fisher, A.T., and C.G. Wheat. 2010. Seamounts as conduits for massive fluid, heat, and solute fluxes on ridge flanks. Oceanography 23(1):74-87.

Goff, J.A. 1991. A global and regional stochastic analysis of near-ridge abyssal hill morphology. Journal of Geophysical Research 96(B13):21,713-21,737.

Goff, J.A., W.H.F. Smith, and K.M. Marks. 2004. The contributions of abyssal hill morphology and noise to altimetric gravity fabric. Oceanography 17(1):24-37.

Hillier, J.K., and A.B. Watts. 2004. "Plate-like" subsidence of the East Pacific Rise-South Pacific superswell system. Journal of Geophysical Research 109(B10):1-20, doi:10.1029/2004JB003041

Hillier, J.K., and A.B. Watts. 2007. Global distribution of seamounts from ship-track bathymetry data. Geophysical Research Letters 34, L13304, doi:10.1029/2007GL029874.

International Hydrographic Organization. 2008 Standardization of undersea feature names. Available online at: http://www.gebco.net/ data_and_products/undersea_feature_names/ (accessed November 17, 2009).

Jaroslow, G.E., D.K. Smith, and B.E. Tucholke. 2000. Record of seamount production and off-axis evolution in the western North Atlantic Ocean, $25^{\circ} 25^{\prime}-27^{\circ} 10^{\prime} \mathrm{N}$. Journal of Geophysical Research 105(B2):2,721-2,736.

Jordan, T.H., H.W. Menard, and D.K. Smith. 1983. Density and size distribution of seamounts in the Eastern Pacific inferred from widebeam sounding data. Journal of Geophysical Research 88(B12):10,508-10,518.

Kitchingman, A., and S. Lai. 2004. Inferences on potential seamount locations from midresolution bathymetric data. Pp. 7-12 in Seamounts: Biodiversity and Fisheries. T. Morato and D. Pauly, eds, Fisheries Centre, University of British Columbia, Canada, Vancouver, BC.

Kitchingman, A., S. Lai, T. Morato, and D. Pauly. 2007. How many seamounts are there and where are they located? Pp. 26-40 in Seamounts: Ecology, Fisheries and Conservation. T.J. Pitcher, T. Morato, P.J.B. Hart, M. Clark, N. Haggan, and R.C. Santos, eds, Fish and Aquatic Resources Series, Blackwell, Oxford, UK.

Lonsdale, P. 1977. Deep-tow observations at Mounds abyssal hydrothermal field, Galápagos Rift. Earth and Planetary Science Letters 36(1):92-110.

Macdonald, K.C., and B.P. Luyendyk. 1985. Investigation of faulting and abyssal hill formation on the flanks of the East Pacific Rise $\left(21^{\circ} \mathrm{N}\right)$ using Alvin. Marine Geophysical Researches 7(4):515-535.
Macdonald, K.C., P.J. Fox, R.T. Alexander, R.A. Pockalny, and P. Gente. 1996. Volcanic growth faults and the origin of Pacific abyssal hills. Nature 380(6570):125-129.

Malinverno, A., and P.A. Cowie. 1993. Normal faulting and the topographic roughness of mid-ocean ridge flanks. Journal of Geophysical Research 98(B10):17,921-17,939.

Marks, K.M. 1996. Resolution of the Scripps/ NOAA marine gravity field from satellite altimetry. Geophysical Research Letters 23(16):2,069-2,072.

Marks, K.M., and W.H.F. Smith. 2006. An evaluation of publicly available global bathymetry grids. Marine Geophysical Researches 27:19-34.

Menard, H.W. 1964. Marine Geology of the Pacific. McGraw-Hill, New York, 271 pp.

National Geophysical Data Center. 2006. 2-minute gridded global relief data (ETOPO2v2). US Department of Commerce, National Oceanic and Atmospheric Administration.

Pitcher, T.J., T. Morato, P.J.B. Hart, M. Clark, N. Haggan, and R.C. Santos, eds. 2007. Seamounts: Ecology, Fisheries and Conservation. Fish and Aquatic Resources Series, 12, Blackwell, Oxford, UK, 527 pp.

Sandwell, D.T., and W.H.F. Smith. 1997. Marine gravity from Geosat and ERS-1 altimetry. Journal of Geophysical Research 102:10,039-10,054.

Sandwell, D.T., and W.H.F. Smith. 2009. Global marine gravity from retracked Geosat and ERS-1 altimetry: Ridge segmentation versus spreading rate. Journal of Geophysical Research 114, B01411, doi:10.1029/2008JB006008.

Sandwell, D.T., and P. Wessel. 2010. Box 3: Seamount discovery tool aids navigation to uncharted seafloor features. Oceanography 23(1):34-36.

Sandwell, D., S.T. Gille, and W.H.F. Smith. 2002. Bathymetry from Space: Oceanography, Geophysics, and Climate. Geoscience Professional Services, Bethesda, MD, 24 pp. Available online at: http://www.geo-prose. com/pdfs/bathy_from_space.pdf (accessed November 17, 2009).

Sandwell, D.T., W.H.F. Smith, S. Gille, E. Kappel, S. Jayne, K. Soofi, B. Coakley, and L. Louis. 2006. Bathymetry from space: Rationale and requirements for a new, high-resolution altimetric mission. Comptes Rendus Geoscience 338:1,049-1,062.

Smith, D.K., and J.R. Cann. 1990. Hundreds of small volcanoes on the median valley floor of the Mid-Atlantic Ridge at $24-30^{\circ} \mathrm{N}$. Nature 348:152-155.

Smith, D.K., and J.R. Cann. 1992. The role of seamount volcanism in crustal construction at the mid-Atlantic ridge. Journal of Geophysical Research 97(B2):1,645-1,658.
Smith, D.K., and T.H. Jordan. 1988. Seamount statistics in the Pacific Ocean. Journal of Geophysical Research 93(B4):2,899-2,918.

Smith, W.H.F. 1998. Seafloor tectonic fabric from satellite altimetry. Annual Review of Earth and Planetary Sciences 26:697-738.

Smith, W.H.F., and D.T. Sandwell. 1997. Global sea floor topography from satellite altimetry and ship depth soundings. Science 277(5334):1,956-1,962.

Smith, W.H.F., and D.T. Sandwell. 2004. Conventional bathymetry, bathymetry from space, and geodetic altimetry. Oceanography 17(1):8-23.

Staudigel, H., and D.A. Clague. 2010. The geological history of deep-sea volcanoes: Biosphere, hydrosphere, and lithosphere interactions. Oceanography 23(1):58-71.

Wessel, P. 2001. Global distribution of seamounts inferred from gridded Geosat/ ERS-1 altimetry. Journal of Geophysical Research 106(B9):19,431-19,441.

Wessel, P., and S. Lyons. 1997. Distribution of large Pacific seamounts from Geosat/ ERS-1: Implications for the history of intraplate volcanism. Journal of Geophysical Research 102(B10):22,459-22,476. 